\title{
CORRECTION OF THE COUPLING RESONANCE IN INTERSECTING STORAGE ACCELERATORS
}

\author{
G. PARZEN
}

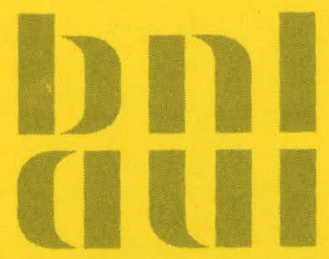

September 22, 1978

\section{ACCELERATOR DEPARTMENT}

BROOKHAVEN NATIONAL LABORATORY ASSOCIATED UNIVERSITIES, INC. UNDER CONTRACT NO. EY-76-C-02-0016 WITH THE UNITED STATES DEPARTMENT OF ENERGY 


\section{DISCLAIMER}

This report was prepared as an account of work sponsored by an agency of the United States Government. Neither the United States Government nor any agency Thereof, nor any of their employees, makes any warranty, express or implied, or assumes any legal liability or responsibility for the accuracy, completeness, or usefulness of any information, apparatus, product, or process disclosed, or represents that its use would not infringe privately owned rights. Reference herein to any specific commercial product, process, or service by trade name, trademark, manufacturer, or otherwise does not necessarily constitute or imply its endorsement, recommendation, or favoring by the United States Government or any agency thereof. The views and opinions of authors expressed herein do not necessarily state or reflect those of the United States Government or any agency thereof. 


\section{DISCLAIMER}

Portions of this document may be illegible in electronic image products. Images are produced from the best available original document. 


\section{ADDENDUM}

BNL 50949

Iñsert to pages 18-19

Table III (Continued)

Process Economics Data ${ }^{a}$

Sector: Synthetic Fuels

\begin{tabular}{|c|c|c|c|c|c|c|c|c|c|c|c|}
\hline \multirow[b]{2}{*}{$\begin{array}{c}\text { Technology/ } \\
\text { Process }\end{array}$} & \multirow[b]{2}{*}{$\begin{array}{l}\text { Uhit Stzeb } \\
\text { (109 Btw } \\
\text { day) }\end{array}$} & \multicolumn{5}{|c|}{ SRI Data } & \multicolumn{4}{|c|}{ Suggested Datag } & \multirow{2}{*}{ Comments $^{h}$} \\
\hline & & $\begin{array}{c}50 C^{c} \\
(175 \$ / \\
10^{6} \mathrm{Btu} / \\
\mathrm{yr})\end{array}$ & $\begin{array}{l}s O C \\
\left(\$ / 10^{6}\right. \\
\text { Btu/yr) }\end{array}$ & $\begin{array}{c}\operatorname{TCI}^{\mathrm{d}} \\
\left(10^{6} \$\right)\end{array}$ & $\begin{array}{l}\text { soce } \\
\left(\$ / 10^{6}\right. \\
\text { Btu })\end{array}$ & $\begin{array}{l}\text { Effif } \\
\text { clency }\end{array}$ & $\begin{array}{c}s 0 C \\
\left(\$ / 10^{6}\right. \\
\text { Btu/yr })\end{array}$ & $\begin{array}{c}\mathrm{TCI} \\
\left(10^{6} \$\right)\end{array}$ & $\begin{array}{l}s \propto c \\
\left(\$ / 10^{6}\right. \\
\text { Btu) }\end{array}$ & $\begin{array}{l}\text { Effi- } \\
\text { clency }\end{array}$ & \\
\hline $\begin{array}{l}\text { 13. Syncrude } \\
\text { from LS/ } \\
\text { LBtu coal }\end{array}$ & . 250 & 9.06 & 10.33 & 925 & 1.01 & 0.66 & 12.25 & $\begin{array}{l}1085 \\
(950- \\
1220)\end{array}$ & $\begin{array}{r}0.55 \\
(0.45 \\
0.65)\end{array}$ & $\begin{array}{c}0.65 \\
(0.63 \\
0.67)\end{array}$ & $\begin{array}{l}\text { H coal process operating } \\
\text { in syncrude mode } 1 \mathrm{~s} \text { as } \\
\text { sumed to be the basis for } \\
\text { these estimates. }\end{array}$ \\
\hline $\begin{array}{l}\text { 14. Syncrude } \\
\text { from HS/ } \\
\text { HBtu coal }\end{array}$ & 250 & 8.90 & 10.15 & 910 & 0.97 & 0.67 & 11.97 & $\begin{array}{l}1060 \\
(920- \\
1200)\end{array}$ & $\begin{array}{r}0.53 \\
(0.40- \\
0.65)\end{array}$ & $\begin{array}{c}0.66 \\
(0.64- \\
0.68)\end{array}$ & $\begin{array}{l}\text { SRI } \quad: R=0.08 ; Y=4 \\
\text { Suggested: } R=0.05 ; Y=5\end{array}$ \\
\hline
\end{tabular}




\title{
CORRECTION OF THE COUPLING RESONANCE IN INTERSECTING STORAGE ACCELERATORS
}

\author{
G. Parzen
}

September 22, 1978

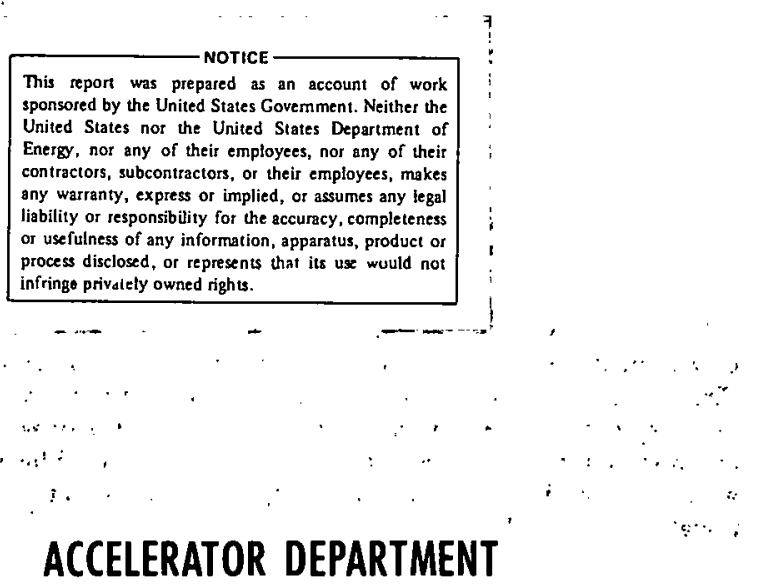

BROOKHAVEN NATIONAL LABORATORY UPTON, NE'W YORK 1.1973 


\section{NOTICE}

This report was prepared as an account of work sponsored by the I Inited States Government. Neither the United States nor the United States Department of Energy (DOE), nor any of their employees, nor any of their contractors, subcontractors, or their employees, makes any warranty, express or implied, or assumes any legal liability or responsibility for the accuracy, completeness or usefulness of any information, apparatus, product or process disclosed, or represents that its use would not infringe privately owned rights.

Printed in the United States of America

Available from

National Technical Information Service

U.S. Department of Commerce

5285 Port Royal Road

Springfield, VA 22161

Price: Printed Copy $\$ 4.00$; Microfiche $\$ 3.00$

January 1979

550 copies 
It is noted that correction of the coupling resonance, $v_{x}-v_{y}=0$, in intersecting storage accelerators with superconducting magnets requires two families of correcting skew quadrupoles with two independent power supplies. A possible location for the two families is suggested, and results are given for the required strengths of the skew quadrupoles and the required accuracy of the corrections. The results are applied to the ISABELLE storage accelerator. 


\section{INTRODUCTION}

The correction of the coupling resonance $\nu_{x}-\nu_{y}=0$ requires a set of skew quadrupoles around the accelerator. It is often assumed that the correction of this resonance requires only one family of skew quadrupoles, with one independent power supply to cancel out the zeroth harmonic of the driving field for this resonance. This is roughly true for many accelerators for which $\Psi_{\mathrm{x}} \sim \Psi_{\mathrm{y}}$, where $\Psi$ is the betatron phase, but it is not true for separated function accelerators for which $\Psi_{x}$ differs appreciably from $\Psi_{y}$ even though $v_{x} \sim v_{y}$, and especially for superconducting accelerators where one of the main error fields driving this resonance arises in the dipoles where $\Psi_{x}$ differs most from $\Psi_{z}$. In separated function accelerators if one assumes that $\Psi_{x}=\Psi_{y}$ at one of the quadrupoles, then one can see the $\Psi_{x}$ differs from $\Psi_{y}$ in the following dipoles, because of the large difference between $\beta_{x}$ and $\beta_{y}$ at the quadrupole, and the rate of change of $\Psi$ with distance goes like $1 / \beta$. In superconducting dipoles, there is a relatively large skew quadrupole error field that drives the coupling resonance, which is due to errors in the positioning of the main dipole coil.

Because of the difference between $\Psi_{x}$ and $\Psi_{y}$, the driving integral of the coupling resonance has both a real and imaginary parts, and two families of skew quadrupoles are required to cancel out the quadrupoles. These two families need to be located around the ring at places where $\Psi_{x}-\Psi_{y}$ for one family differs by roughly $\pi / 2$ from the $\Psi_{x}-\Psi_{y}$ for the second family. A convenient location for these two families of quadrupoles, where this condition on $\Psi_{x}-\Psi_{y}$ is likely to be roughly fulfilled, is to put them in or near the quadrupoles which are just on either side of the crossing point in intersecting storage accelerators like ISABELLE, with one family on one side of the crossing point and the other family on the other side of crossing point. The phase shift difference $\Psi_{x}-\Psi_{y}$ near the crossing point is given by (see Section II)

$$
\Psi_{x}-\Psi_{y}=\tan ^{-1}\left(s / \beta_{x}^{*}\right)-\tan ^{-1}\left(s / \beta_{y}^{*}\right) \text {, }
$$

where $\beta_{x}^{*}$ and $\beta_{y}^{*}$ are the $\beta$ - functions at the crossing point. Because $\beta_{x}^{*}$ and $\beta_{y}^{*}$ usually differ considerably at the crossing point, the above result for $\Psi_{x}-\Psi_{y}$ is not zero and changes sign on either side of the crossing point, so that $\Psi_{x}-\Psi_{y}$ can differ considerably for two points on opposite sides of the crossing point.

\section{THEORY}

The strength of the $\nu_{x}:-v_{y}=0$ resonance is determined by the integral ${ }^{1}$

$$
C=\frac{1}{2 \pi} \int \mathrm{ds}\left(\beta_{x} \beta_{y}\right)^{\frac{1}{2}} \frac{1}{B_{p}} \frac{\partial B_{x}}{\partial x} \exp .\left[i\left(\Psi_{x}-\Psi_{y}-\epsilon^{\theta}\right)\right] \text {. }
$$

$\epsilon_{-}=\nu_{x}-\nu_{y}$ and is the distance of the tune from the resonance line. $\theta=s / \bar{R}$, where $\frac{Y}{R}$ is the average radius of the accelerator. $\Psi_{x}$ and $\Psi_{y}$ are the betratron phases,

$$
\Psi_{x}=\int_{0}^{s} d s / \beta_{x}, \text { and } \Psi_{y}=\int_{0}^{s} d s / \beta_{y}
$$

The quantity $C$ can be interpreted as the resonance width and determines the

1. G. Guignard, CERN 77-10 (1977). 
degree of coupling between the horizontal and vertical motions, and also the shift in the $\nu$-values. If we assume that $\epsilon \simeq .01$, then the $\varepsilon \theta$ term can be neglected.

One sees from (2.1) that the resonance is driven by the random skew quadrupole field errors. In order to correct out the coupling resonance, one needs skew quadrupoles located around the ring which can be adjusted to cancel the value of $C$ produced by the random skew quadrupole field errors. In general, $C$ has both real and imaginary parts, and 2 families of skew quadrupole with 2 independent power supplies are required to cancel $\mathrm{C}$. . An exception to this is an accelerator for which $\Psi_{x} \sim \Psi_{y}$, or for which $\Psi_{x} \sim \Psi_{y}$ at those 10cations where most of the skew quadrupole field errors occur. In separated function accelerators, if one assumes $\Psi_{x}=\Psi_{y}$ at one of the quadrupoles then one can see that $\Psi_{x}$ differs from $\Psi_{y}$ in the following dipoles, because of the large difference between $\beta_{x}$ and $\beta_{y}$ at the quadrupole, and the rate of change of $\Psi$ with distance goes like $1 / \beta$. In superconducting dipoles, there is a relatively large skew quadrupole error field due to errors in the positioning of the main dipole coil. The above indicates that accelerators which have separated function lattices and superconducting dipoles require 2 families of skew quadrupoles to correct the coupling resonance.

The two familes of skew quadrupoles needed to correct the coupling resonance have to be located around the ring at places where $\Psi_{x}-\Psi_{y}$ for one family differs by roughly $\pi / 2$ from the $\Psi_{x}-\Psi_{y}$ for the second family. A convenient location for these two families of quadrupoles, where this condition on $\Psi_{x}-\Psi_{y}$ is likely to be roughly fulfilled, is to put them in or near the quadrupoles which are on either side of the crossing point in intersecting storage accelerators like ISABELLE, with one. family on one side of the crossing point and the other family on the other side of the crossing point. Since near the crossing point $\beta_{x}$ and $\beta_{y}$ vary like

$$
\begin{aligned}
& \beta_{x}=\beta_{x}^{*}+s^{2} / \beta_{x}^{*}, \\
& \beta_{y}=\beta_{y}^{*}+s^{2} / \beta_{y}^{*},
\end{aligned}
$$

where $\beta_{x}^{*}, \beta_{y}^{*}$ are the $\beta$ - functions at the crossing point, then one finds for $\Psi_{x}-\Psi_{y}$

$$
\Psi_{x}-\Psi_{y}=\tan ^{-1}\left(s / B_{x}^{*}\right)-\tan ^{-1}\left(s / B_{y}^{*}\right)
$$

Because $\beta_{\mathrm{x}}$ and $\beta_{\mathrm{y}}$ usually differ considerably at the crossing point, the above result for $\Psi_{x}-\Psi_{y}$ is not zero and changes sign on either side of the crossing point, so that $\Psi_{x}-\Psi_{y}$ can differ considerably for two points on opposite sides of the crossing point. For the ISABELLE lattice, $s=30 \mathrm{~m}$ from the crossing point to the first quadrupole, $\beta_{y}^{*}=7.5 \mathrm{~m}, \beta_{x}^{*}=30 \mathrm{~m}$, and one finds that $\Psi_{x}-\Psi_{y}$ changes by $.34 \pi$ between the two quadrupoles which are on either side of the crossing point.

It will now be assumed that the two families of correcting skew quadrupoles are placed near or at the quadrupoles on either side of each crossing point. The corrections to the left of the crossing point will produce the field $B=B_{0} a_{1, L} x$, and those to the right the field $B=B_{O} a_{1}, R_{R}$, where $B_{O}$ is the main dipole field. The contribution to the width of the coupling resonance due to the correctors can be calculated from Eq. (2.1) as 


$$
\begin{aligned}
C=\frac{1}{2 \pi} N L\left(\beta_{x} \beta_{y}\right)^{\frac{1}{2}} & {\left[\left(a_{1, L}+a_{1, R}\right) \cos \bar{\Psi}\right.} \\
& \left.+i\left(a_{1, L}-a_{1, R}\right) \sin \bar{\Psi}\right],
\end{aligned}
$$

where $\mathrm{N}$ is the number of crossing points, $\mathrm{L}$ is the length of each corrector, $\Psi=\Psi_{x}-\Psi_{y}$ at the left corrector and can be computed from Eq. (2.3). Eq. (2.4) can be solved for $a_{1, L}$ and $a_{1, R}$ and gives

$$
\begin{aligned}
& a_{1, L}=\frac{1}{2}\left[C_{R} / \cos \dot{\Psi}+C_{I} / \sin \bar{\psi}\right] /\left(N L\left(\beta_{x} \beta_{y}\right)^{\frac{1}{2}} / 2 \pi \rho\right), \\
& a_{1, R}=\frac{1}{2}\left[C_{R} / \cos \Psi-C_{I} / \sin \ddot{\psi}\right] /\left(N L\left(\beta_{x} \beta_{y}\right)^{\frac{1}{2}} / 2 \pi \rho\right),
\end{aligned}
$$

where $C_{R}$, and $C_{I}$ are the real and imaginary parts of $C$.

In order to estimate the required capacity of the skew quadrupole correctors, it is assumed that the rms values of $C_{R}, C_{I}$ and $|C|=\left[C_{R}^{2}+C_{I}^{2}\right]^{\frac{1}{2}}$ due to random field errors are known. The required capacity $a_{1, L}$ and $a_{1, R}$ may then be estimated 'by

$$
a_{1, L}=S F \times C_{r m s}\left[1 / \cos ^{2} \psi+1 / \sin ^{2} \Psi\right]^{\frac{1}{2}} /\left(N L\left(\beta_{x} \beta_{y}\right)^{\frac{1}{2}} / 2 \pi \rho\right),
$$

where SF is some safety factor and $C_{r m s}$ is the rms value of $|c|$.

Accuracy of Correction

The required accuracy of the power supplies for the skew quadrupole correctors is determined primarily by the degree of coupling that can be tolerated. If the width of the resonance $|c|$, is corrected with an error of $\Delta C$, then the remaining coupling between horizontal and vertical motions is given roughly by ${ }^{1}$

$$
\mathrm{x} / \mathrm{y}=\Delta \mathrm{C} /\left(2\left|\nu_{\mathrm{y}}-\nu_{\mathrm{x}}\right|\right)
$$

If it is assumed that a remaining coupling of .01 can be tolerated, then the required accuracy is given by

$$
\Delta \mathrm{C} / \mathrm{C} \leqslant .02\left|\nu_{y}-\nu_{\mathrm{x}}\right| / \mathrm{C}
$$

Another effect of errors in the correctors is to produce a shift to the $v$-values of the normal modes. This is a second order effect and is probably negligible compared to the $(x, y)$ coupling. The shift in $v$-value is given roughly by

$$
\Delta v=(1 / 4) \Delta c^{2} /\left|\nu_{x}-\nu_{y}\right|
$$

If it assumed that only $1 \%$ coupling is permitted, and $\Delta \mathrm{C}$ is given by Eq. (2.8), then $v$ can be written as

$$
\Delta \nu \approx 1 \times 10^{-4}\left|\nu_{\mathrm{y}}-\nu_{\mathrm{x}}\right|
$$


Thus the $v$ - shift due to errors in the corrector power supply will be quite small of the order of $10^{-6}$ for $\left|\nu_{y}-\nu_{x}\right| \simeq 10^{-2}$.

\section{APPLICATION TO ISABELLE}

The variation of $\Psi_{x}-\Psi_{y}$ with distance near the crossing point is shown in Fig. 1 for the ISABELLE accelerator. Also shown are the location of the quadrupoles closest to the crossing point, Q1, Q2 and Q4. One sees that the two families of correcting skew quadrupoles can be placed at either the Q1 quadrupoles or the $Q 2$ quadrupoles since $\Psi_{x}-\Psi_{y}$ differs considerably from one side of the crossing point to the other for cither Q1 or Q2. On the other hand $Q 4$ is not a good choice since $\Psi_{x}-\Psi_{y} \approx 0$ at Q4 on either slde of the crossing point.

The width of the coupling resonance in ISABELLE due to random field errors be computed from the expected field errors, giving the result ${ }^{2}$

$\mathrm{C}_{\mathrm{rms}}=.015$.

The required capacity of the correcting skew quadrupoles can be computed from Eq. (2.6). Assuming that the correcting skew quadrupoles are located at $\mathrm{Q} 1$, have a length of $2.2 \mathrm{~m}$ and a safety factor of $\mathrm{SF}=3$, one finds the required capacity of $a_{1, L}=a_{\perp}, R=2.4 \times 10^{-3} / \mathrm{cm}$. The same result holds if the correcting skew quadrupoles are located at $Q 2$.

The required accuracy in power supplies for the correcting skew quadrupole is given by Eq. (2.8). Assuming that $\left|v_{y}-v_{x}\right| \approx .01$, one finds the tolerance on the remaining resonance width after correction of $\Delta \mathrm{C}=2 \times 10^{-4}$. With a safety factor of 3 , the correction quadrupoles have a capacity to correct a resonance width of $\mathrm{C}=.09$ or $400 \mathrm{GeV}$, and thus the required accuracy of the power supply at $400 \mathrm{GeV}$ is $2 \times 10^{-3}$. In order to be satisfactory at $30 \mathrm{GeV}$ also, the required power supply rating is $1 \times 10^{-4}$.

The remaining shift in the $\nu$-value after correction may be computed from Eq. (2.9). For $\left|v_{y}=x\right|=.01$, one finds $\Delta v=10^{-6}$.

It has been noted by $R$. Chasman and M. Month ${ }^{3}$ that the correctors for the coupling resonance will have to correct not only the coupling introduced by field errors in the accelerator but also the coupling introduced by the vertical dispersion correction system. At present, it is planned to correct the vertical dispersion at the crossing points by vertical displacement of the closed orbit 4 and it has been found in computer simulation studies using the CLOSORB program that this method of correcting the vertical dispersion does not affect the coupling present by very much.

\section{ACKNOWLEDGEMENT}

I wish to thank E.D. Courant for helpful discussions.

\section{Distr.: External}

2. A result for the width of the coupling resonance was found by $A$. Chao, Proc. 1975 ISABELLE Summer. Study, BNL 20550, p. 386, for the $200 \mathrm{GeV}$ ISABELLE. The result given in this paper was found by G. Parzen through a computer simulation study of the $400 \mathrm{GeV}$ ISABELLE using the CLOSORB program.

3. R. Chasman and M. Month, BNL Accelerator Dept. Report ISA 76-10 (1976).

4. G. Parzen, BNL Accelerator Dept. Report, ISA 78-10, (1978). 


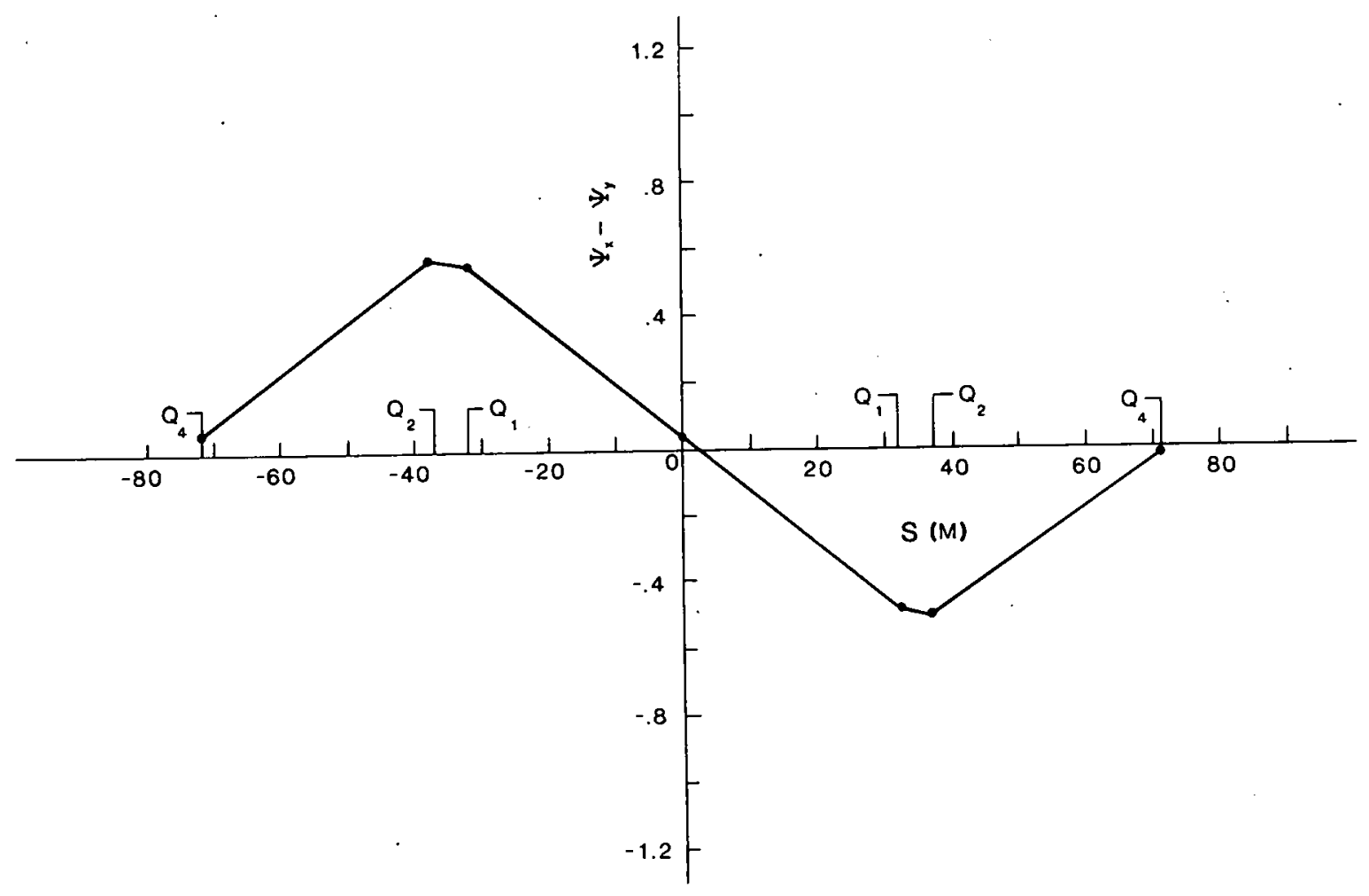

Figure 1. - 
